\title{
Como caracterizar qualidade em relação à produção da Rede Globo de Televisão?
}

\author{
Elizabeth Bastos Duarte \\ UFSM - Brasil - bebethb@terra.com.br \\ Graduada em Letras pela Universidade Federal do Rio Grande do Sul \\ e Pós-doutora em Televisão pela École des Hautes Études en Sciences Sociales \\ e pela Université de Paris III Sorbonne Nouvelle (França). \\ É pesquisadora IC do CNPq e atua no PPGCOM da Universidade Federal de Santa Maria.
}

\begin{abstract}
Resumo
No Brasil, as grandes cadeias de televisão aberta com atuação em todo o território nacional são empresas privadas cuja atuação é presidida por uma lógica econômica tendo em vista os lucros e as vantagens que possam obter. $\mathrm{O}$ presente trabalho propõe-se a estabelecer alguns critérios que permitam definir o que se pode considerar, nesse mercado tão disputado, qualidade em televisão, analisando diferentes aspectos responsáveis pela posição dominante ocupada pela Rede Globo de Televisão (RGT) que a tornam não só líder de audiência, como referência para a produção/programação das demais.
\end{abstract}

Palavras-chave

TV aberta, Telejornalismo, Rede Globo de Televisão, Qualidade da TV.

\begin{abstract}
In Brazil, the big public-access television channels that operate all over the country are private companies. Their operations are hold by the economical logic, considering the profits and benefits that they may obtain. This paper aims to set up a some criteria in order to define what can be considered, regards this competitive market, television quality, analyzing several aspects responsible for the prevailing position occupied by Rede Globo de Televisão (RGT), aspects that make the company not only an audience leader but the reference to the other television channels.
\end{abstract}

Keywords

Public-access TV, Telejournalism, Rede Globo de Televisão, TV quality.

Artigo recebido em 28/09/2012

Aprovado em 15/05/2013 


\section{7 anta diversidade! Televisão pública? Televisão privada? Televisão estatal? Canais educativos? Contextos midiáticos que se alteram de um país a outro; preferências por diferentes gêneros, temáticas, formatos e tons.}

A discussão sempre presente sobre a qualidade em televisão vem oscilando entre questões éticas, estéticas, narrativas, tecnológicas, entre outras. Os brasileiros, em particular, a relacionam com a Rede Globo de Televisão: afinal, a sua produção tornouse referência para todas outras emissoras no Brasil.

Sem ignorar os diferentes pontos de vista, parte-se do pressuposto de que a qualidade em televisão só pode ser definida a partir da consideração às características, âmbito de atuação e funções desse meio de comunicação de massas; e, mais que tudo, à natureza do tipo de produto que veicula: os programas televisuais são produções coletivas, para as quais concorrem inúmeros enunciadores; a televisão, uma mídia que vive do consumo dos produtos que disponibiliza ao mercado.

Trata-se de uma indústria de discursos, construídos a partir da gramática do televisual, cujas normas mais gerais são a serialização e a consequente fragmentação de suas narrativas; a mobilização e articulação de diferentes gêneros e de linguagens sonoras e visuais para sua expressão, sobredeterminadas pelos meios técnicos de produção, circulação e consumo dessas narrativas. Assim, a qualidade desses produtos, os programas televisuais, está relacionada à competência e à criatividade demonstradas na estruturação e realização de seus relatos; aos recursos discursivos e expressivos, convocados para sua manifestação; às tecnologias utilizadas para qualificar sua realização, difusão e consumo, tendo em vista as funções pelas quais a televisão se consagrou - entretenimento, informação, educação -, e a necessária aprovação e consumo por parte de seu público-alvo, os telespectadores. Quanto aos aspectos éticos a eles relacionados, eles são de difícil avaliação, na medida em que variam segundo a cultura e a ideologia.

No contexto brasileiro, onde a televisão nasceu como empresa privada, regida pelas leis do mercado, essas questões teriam passado desapercebidas, não fosse o fato de as emissoras (canais abertos) se sustentarem com a venda de espaços comerciais, cujo valor é proporcional à audiência por ela obtida em um determinado horário: daí a 
importância de oferecer ao mercado televisual produtos de qualidade, capazes de despertar o interesse e conquistar o telespectador, contando, se possível, com a aprovação da crítica especializada. Trata-se de um negócio que depende da audiência. Em razão disso, não se pode esquecer, quando se examina a qualidade de um programa, de que se está frente a um mercado extremamente disputado e de que os produtos por ele disponibilizados ao consumo dos telespectadores estão integrados aos princípios que regem a produção das mercadorias em geral: as emissoras buscam sempre oferecer novas séries de produtos que se apresentem como novidades, mesmo que se trate da repetição de tudo o que já foi testado e deu certo. Esse é o caso das ficções brasileiras telenovelas, seriados, minisséries -, em particular, as produzidas pela Rede Globo, que detêm alto valor comercial no mercado de produção televisual, tanto em nível nacional, como internacional.

$\mathrm{Na}$ tentativa, por razões mercadológicas, de se sobrepor e distinguir das outras grandes emissoras de TV do país, a Rede Globo apropriou-se, pioneiramente, do discurso da qualidade, passando, em razão dessa decisão estratégica, a dominar a audiência, e, consequentemente, a definir os padrões de qualidade a serem perseguidos pelas demais emissoras: sua produção tornou-se referência de qualidade, objeto de respeito, admiração e imitação por parte das demais.

Atualmente, os programas realizados pela Rede Globo vêm passando por significativas transformações, devido não só às lógicas e interesses que presidem a sua produção discursiva e às múltiplas funções que a emissora hoje arroga para si, como ao estilo que vem imprimindo a esses produtos, com a corroboração das novas tecnologias de produção, circulação e consumo dos produtos televisuais. Embora as repercussões dessas alterações sejam extensivas à produção televisual da emissora como um todo, a reflexão aqui desenvolvida toma como principal referência os produtos ficcionais por ela realizados, com vistas a dimensionar as interferências da incorporação dessas transformações mais recentes em sua organização narrativa, na definição dos procedimentos discursivos adotados, enfim, na qualidade de seus produtos, e as suas repercussões na gramática de formas de expressão do televisual. 


\section{Panorama geral: a Rede Globo de Televisão}

A Rede Globo de Televisão (RGT) ${ }^{1}$, a segunda maior rede de televisão comercial do mundo, faz parte do maior conglomerado midiático brasileiro, as Organizações Globo $^{2}$. Líder absoluta de audiência no país, é assistida diariamente por 150 milhões de pessoas no Brasil, ou no exterior, via TV Globo Internacional, atingindo 98,44\% do território brasileiro: cobre 5.482 municípios e cerca de 99,5\% da população.

Sua sede administrativa está localizada no bairro Jardim Botânico, na Zona Sul do Rio de Janeiro, onde também fica situado seu departamento de jornalismo. Seus principais estúdios de produção encontram-se no complexo conhecido como Projac, em Jacarepaguá, na Zona Oeste da cidade. A emissora conta também com estúdios de produção em Vila Cordeiro, São Paulo, nos quais ainda funciona um departamento de jornalismo e a partir dos quais transmite parte da programação da rede.

No ar há quase cinquenta anos, a RGT, inicialmente com o apoio da ditadura militar, vem se dedicando a implantar e conservar aquilo que se tornou conhecido como o Padrão Globo de Qualidade. Trata-se de uma ideologia geradora de um conjunto rigoroso de regras, implícitas e explícitas, que norteiam suas operações, implementadas a partir do know-how repassado a ela pela Time-Life, devido a acordo estabelecido entre as duas emissoras, ainda na década de 1960. A partir de então, a atuação da Globo vemse distinguindo em relação às práticas de outras emissoras de televisão do país; trata-se de uma maneira de fazer televisão, centrada em um modelo empresarial, cujo foco são os setores comercial e produtivo. A adoção desse modelo, já consolidado na televisão americana, representou também grandes avanços em termos técnicos e tecnológicos, pois, além de receber um gerenciamento direto, a parceria resultou no treinamento de funcionários da Globo nos Estados Unidos.

Passando a conferir - por motivos óbvios - especial atenção ao setor comercial,

1Fundada em 26.04.1965, na cidade do Rio de Janeiro.

2 À RGT estão associadas a Globo Filmes (empresa cinematográfica), a Rede Globo Internacional (difusão internacional), a Globo Marcas (branding e publicidade), a Globo Vídeo (vídeo na internet), a TV Globo Minas (emissora de televisão em Belo Horizonte), a TV Globo Brasília (televisão estação de Brasília), a TV Globo Nordeste (estação de televisão em Recife), a TV Globo Rio de Janeiro (estação de televisão no Rio de Janeiro) e a TV Globo São Paulo (estação de televisão em São Paulo). 
a RGT substituiu o modelo do patrocinador único, responsável por determinados programas, pelo de venda de espaços intervalares, fundado na adoção de uma programação fixa e na negociação de espaços publicitários em intervalos comerciais abertos no desenrolar das emissões, o que lhe vem permitindo obter maiores lucros e, consequentemente, mais autonomia no desenvolvimento de sua grade de programação.

$\mathrm{O}$ gerenciamento eficiente desse forte esquema comercial de marketing e publicidade tem valido à RGT muito dinheiro. Somente em 2009, a emissora faturou, em publicidade, $\mathrm{R} \$ 7$ bilhões, correspondentes a 73,5\% de toda a receita publicitária da TV aberta brasileira. A publicidade virtual, implantada de maneira pioneira pela TV Globo em 1996, transformou-se hoje em um novo paradigma de comercialização. Para conferir presteza e qualidade a seu atendimento, a emissora desenvolveu sistemas como o Sis.com, que permite a venda de espaços comerciais online e aproxima os clientes da empresa; e o SIM, sistema de informações de mídia, que possibilita às afiliadas e agências construírem seus próprios planos de mídia. Tais inovações e o lucro com elas obtido vêm conferindo maior sustentação ao padrão de qualidade pretendido pela emissora.

Contando, em sua diretoria, com executivos de reconhecida competência e dispondo dos melhores profissionais do mercado em cada uma de suas áreas de sustentação, a emissora funda seu êxito no permanente controle e difusão do padrão Globo de qualidade. Para tanto conta como suportes, com:

(1) estrutura de funcionamento ágil e eficiente que permite a ampliação de seu âmbito de atuação - a RGT, que começou a funcionar como uma rede de emissoras afiliadas por todo o país em $1^{\circ}$ de setembro de 1969 , opera atualmente com cinco emissoras próprias, a Globo-RJ (RJ), a Globo-SP (SP), a Globo-DF (Brasília), Globo-MG (BH) e a Globo-NE (Recife) e 147 redes afiliadas, pertencentes a empresas de terceiros, além da TV Globo Internacional e dos serviços mediante assinatura no país (canais pagos).

(2) excelência técnica na difusão da sua programação - a RGT, em busca de recepção fácil de sinal, abrangência da cobertura e boa definição de imagem, realiza permanentes e pesados investimentos na infraestrutura necessária à expansão da 
Estudos em Jornalismo e Mídia - Vol. $10 \mathrm{~N}^{\circ} 2$ - Julho a Dezembro de 2013

televisão para todo o país: cobre através de sinal terrestre $98,53 \%$ do território nacional; transmite seu sinal via cabo e via satélite para os canais pagos em parceria com suas principais afiliadas, além de contar com $100 \%$ de cobertura nacional através de antena parabólica. A Rede Globo Internacional opera canais de televisão via satélite em todo o mundo, inclusive nas Américas, Oceania, Europa, Oriente Médio, África e Japão. Globo.com, o portal de internet da empresa, disponibiliza grande biblioteca de vídeos históricos; fornece parte do conteúdo atual gravado e acesso a outros produtos da Organização, tais como revistas, jornais e rádio ao vivo. $\mathrm{O}$ domínio atraiu pelo menos 1,8 milhão de visitantes anualmente, até 2008; atualmente, é classificado pela Alexa como o $105^{\circ}$ site mais acessado no mundo.

(3) instalações confortáveis e bem equipadas - a RGT tem apostado na ampliação e criação de novos parques industriais televisivos: na década de 1990, a emissora inaugurou, no Rio de Janeiro, o Projac, uma cidade cenográfica muito bem equipada, e estabeleceu em São Paulo novos estúdios jornalísticos, dividindo entre os dois estados sua produção de ficção e jornalismo.

(4) disponibilização de tecnologias de ponta - a RGT investe pesado em tecnologia da informação, estratégia que lhe rende o primeiro lugar no mercado de mídia e comunicação, garantindo com isso segurança na informação veiculada; transações comerciais via internet; automação dos procedimentos administrativos; mobilidade na transmissão de dados ${ }^{3}$.

3A disponibilização de tecnologia da informação de ponta atua, dessa forma, em benefício da emissora em diferentes setores. Assim, por exemplo: (a) a conexão por fibra ótica digital de alta velocidade para troca de matérias e interligação dos sistemas de informação permite a integração do trabalho de jornalistas das emissoras do Rio de Janeiro, São Paulo, Belo Horizonte e Brasília e de mais de 30 afiliadas; (b) a transmissão, desde 1998 em alta definição (HDTV), possibilita maior qualidade de imagem; (c) a digitalização, desde 2007, das imagens da TV e o fornecimento de sinal digital a 27 cidades brasileiras ampliam o âmbito e qualidade de sua atuação; (d) a operação com dez unidades móveis (UMS), totalmente digitalizadas, garante maior qualidade na produção, transmissão ou geração de conteúdo virtual; (e) a digital backlot possibilita a extensão virtual de cenários, com a geração de ambientes virtuais a partir de captação de locações reais e utilização de mais de uma câmera; (f) o Globocop, o mais completo helicóptero construído, totalmente digital e HDTV, confere maior agilidade e precisão na caça à informação; (g) a telemetria, sistema que permite acompanhar os atletas durante as competições, permite o monitoramento dos batimentos cardíacos, da velocidade de deslocamento, das distâncias percorridas e outras informações; (h) a infraestrutura de acesso ao iNews, à internet e aos serviços da rede corporativa oferece apoio e confere maior agilidade às equipes de redação; (i) o Scout, sistema de estatísticas, enriquece as transmissões de partidas de futebol com o fornecimento de dados para orientar as análises dos comentaristas e narradores; (j) o desenvolvimento de tecnologia interativa possibilita a utilização de 
Mas a construção do que hoje se chama Padrão Globo de Qualidade, para além dessa infraestrutura competente e capacitada, está estreitamente ligada, como não poderia deixar de ser, ao setor produtivo da emissora, responsável pela realização da maior parte dos programas de sua grade, cuja meta principal é o aumento do consumo de sua programação e dos produtos por ela ofertados ao mercado televisual, traduzido em termos de audiência e participação do telespectador.

\section{Sobre a produção global}

A Globo produz a maior parte dos programas que exibe e adota um formato fixo de programação, ou seja, uma grade fixa, tanto na vertical (sequência dos programas no dia), quanto na horizontal (a sequência ao longo dos dias da semana), na qual o horário nobre é preenchido com duas novelas de temática mais leve, encaixadas por telejornais curtos e sintéticos (o jornal local e o Jornal Nacional), uma telenovela de produção nobre e com enredo mais forte, a atual novela das nove e, a partir das $22 \mathrm{~h}$, com uma linha que comporta filmes, futebol, seriados e mininovelas produzidos pela emissora e reportagens (Globo repórter), todos apresentados com bastante regularidade de horário e programação. Essa grade vem sendo mantida com pequenas alterações desde 1976, sendo fielmente cumprida pela emissora, exceto aos verões, após as $22 \mathrm{~h}$, quando a programação do horário é substituída por minisséries, reprises de filmes e o Big Brother Brasil. A permanência desse padrão tem sido decisiva para a conquista da liderança de audiência.

No que concerne especificamente aos programas da Globo, sua qualidade temlhe valido prêmios nacionais e internacionais e a exportação de muitos deles para mercados internacionais. É verdade que a RGT vem, ao longo dos anos, apostando

vários mecanismos de votação, por meio de telefone fixo, mensagens de celular ou votos pela internet; (k) a implantação do sistema de apuração de interatividade (SAI) assegura que a transmissão das informações, chegadas à emissora, sejam postas à disposição do diretor do programa; (I) a disponibilização do painel de controle do produto permite ao produtor acesso às informações mais relevantes para a gestão de um produto (datas de exibição, status de gravação das cenas, status da pósprodução, frentes de texto e de gravação, andamento das gravações do dia, etc.). 
maciçamente na produção ficcional, em particular, nas telenovelas, o carro-chefe da emissora. Exibe atualmente cinco telenovelas diárias em sua programação, sendo considerada uma das maiores produtoras de telenovelas do planeta. Ora, fazer jus a isso significa contar com os mais competentes escritores, roteiristas, diretores e produtores do país; com uma equipe de técnicos altamente capacitados na captação de imagens, montagem, edição; com um elenco permanente de grandes nomes, atores e apresentadores; enfim, com equipes de profissionais - os núcleos de produção que a emissora mantém - capazes de dar conta da realização desses produtos ficcionais com a qualidade necessária para sua inserção na grade de programação da Rede Globo. Em síntese, significa, mais que tudo, dotar de identidade todos os produtos realizados pela emissora, de tal forma que os telespectadores reconheçam, de pronto, que se trata de uma produção Globo.

Assim, o pressuposto que norteia as ações da Globo é o de que uma televisão de qualidade planetária deve dispor não apenas de infraestrutura capacitada e de tecnologia de última geração em todos os setores de abrangência de sua ação, mas também de um setor produtivo capaz de recorrer a soluções criativas, por vezes até mesmo artesanais, que marquem sua teledramaturgia de traços nacionais, acrescidos de um tom e estilo que identifiquem a emissora, dotando sua produção como um todo de características arrojadas, cenários e figurinos hollywoodianos, efeitos especiais retumbantes etc. Esse propósito perpassa todo o processo de criação e produção de programas ficcionais séries, minisséries, mininovelas e telenovelas - de forma a distingui-los dos de outras emissoras. Em razão disso, a RGT mantém núcleos permanentes de experimentação para testes e lançamento de novos formatos, proposições de novas linguagens e estéticas, com vistas à realização e veiculação de produtos que cativem o telespectador e que, se possível, sejam aplaudidos pela crítica.

O modelo tradicionalmente adotado pela Globo na estruturação de suas narrativas ficcionais, funda-se na serialização, que obriga à segmentação dos relatos em capítulos, episódios, edições; na fragmentação dos capítulos e/ou episódios em blocos, para comportar os espaços comerciais (o que passou a exigir o emprego de estratégias que criassem miniclímax e suspenses a cada intervalo comercial, capítulo ou 
Estudos em Jornalismo e Mídia - Vol. $10 \mathrm{~N}^{\circ} 2$ - Julho a Dezembro de 2013

episódio); na adequação das narrativas ao público disponível no horário de exibição; nas transposições de sentidos tanto no interior de sua programação, como de uma mídia para outra, decorrentes das apropriações de conteúdo operadas na construção desses relatos que recuperam textos veiculados por outras mídias, via adaptações, remakes e/ou referências a outros discursos; na adoção do princípio da obra aberta, o que significa iniciar o relato televisual com a história ainda não definida e/ou concluída, possibilitando, com isso, correções e/ou alterações de percurso no desenrolar do relato.

Mas esse modelo estrutural vem aos poucos se complexificando, tendo em vista a decisão estratégica da emissora de invadir, ou seja, de ocupar parte do espaço interno dos programas para responder a outros interesses: uma mera observação dos conteúdos postos em circulação pela Globo em sua programação, em campanhas e nos sites da empresa, evidencia seu esforço para mostrar uma imagem de qualidade também ligada à responsabilidade social, ao compromisso com a democracia e com o pluralismo cultural. Dessa maneira, não só seu departamento comercial vem sobrecarregando o interior dos textos dos programas com os merchandisings publicitários de toda ordem que interferem grosseiramente nas tramas narrativas, como ela própria vem investindo pesado na autorreferenciação descarada à sua própria produção, na autopromoção de sua imagem e de seu fazer, na divulgação da competência de seus executivos, de seu elenco permanente, na qualidade e aceitação de seus produtos.

Mais ainda, com o passar dos anos e o sucesso obtido pela equipe, a Globo foi incorporando a todos os seus produtos um jeito de fazer televisão introduzido pelo Núcleo Guel Arraes, uma unanimidade de crítica e público, que, aos poucos, foi sendo alçado ao status de grife de qualidade da Globo, sendo identificado com a própria renovação da linguagem da TV no Brasil. Assim, os outros núcleos de produção da emissora passaram a apropriar-se, por vezes de forma grosseira, do estilo, tom e estratégias sofisticadas empregadas pelo Núcleo do Guel Arraes em suas narrativas, de certa forma, banalizando-as.

Somam-se ainda a essas pretensões de qualidade e identidade da RGT o desejo atual da emissora, talvez para se redimir pelos anos de conivência com a ditadura, de ter 
sua imagem associada não apenas à oferta de uma produção televisual de vanguarda, mas também ligada à identidade nacional e aos problemas sociais vivenciados pelos brasileiros.

\section{Sobre os núcleos de produção}

Ciente de que a televisão, como qualquer outra mídia, está em constante transformação, a RGT, como já se referiu, mantém vários núcleos de produção, responsáveis pela realização de seus produtos ficcionais, dentre os quais, ao que tudo indica, o que melhor corresponde às expectativas da emissora, às pretensões ética, estética e social do padrão Globo de qualidade, é o Núcleo Guel Arraes ${ }^{4}$. As realizações do referido núcleo, que é assessorado por um grupo de profissionais de indiscutível competência, caracteriza-se por um tom específico, iconoclasta e metalinguístico, fundado na irreverência e rebeldia em relação à própria $\mathrm{TV}$, sendo responsável pela proposição de um novo modelo de fazer televisual no país, bem como por uma reconfiguração das formas de tratamento do humor em televisão.

A produção do Núcleo distingue-se: (a) do ponto de vista temático, pela clara intenção de valorização da cultura brasileira, reinterpretando a realidade social e a produção cultural do país, a partir de perspectivas não-oficiais, do popular e do periférico, explorando a diversidade cultural e investindo na divulgação das manifestações artísticas e culturais da periferia das grandes regiões metropolitanas do país, difundindo conteúdos que estimulam a crítica social (desigualdades econômicas, costumes, preconceitos raciais e de classe etc.) e a afirmação cultural; (b) do ponto de vista discursivo e expressivo, pela proposição sistemática de novos formatos, pela realização de episódios, séries e sitcoms genuinamente brasileiros, a partir de roteiros originais ou adaptados, em alguns casos, por escritores contemporâneos, enfim, pela nítida pretensão de explorar recursos técnico-expressivos da televisão e de fazer do

4 Criado em 1991 pelo diretor que lhe dá nome. 
experimentalismo formal uma marca da produção global.

Assim, além da abordagem criativa desse tipo de temática e do investimento em formatos e recursos inovadores, a produção do Núcleo começou a testar o uso de estratégias discursivas até então pouco empregadas pelo discurso ficcional televisivo, tais como: a deliberada indistinção entre o ficcional e o não-ficcional, entre o telejornalismo (registro documental) e a teledramaturgia, entre a televisão e o real; a exposição crítica dos produtos, processos e modelos de representação consolidadas pela tevê; o exercício permanente de metalinguagem; a descarada intertextualidade com outros meios (cinema, teatro, literatura, artes performáticas); a paródia em relação aos próprios gêneros televisuais, renovando, com isso, entre outros, o tratamento do humor pela Rede Globo; a proposição, em suma, uma TV inteligente que, ao escancarar suas fórmulas e clichês, ao revelar de alguma maneira que toda a encenação é encenação, ri, antes de mais nada de si mesma, apresentando a própria realidade como uma construção de linguagem.

Ocorre que a apropriação descuidada, a incorporação apressada desse estilo e o uso indiscriminado e reiterado desses procedimentos discursivos bastante complexos pelos outros núcleos, aliados às outras decisões estratégicas da emissora, já referidas, podem comprometer os ideais de qualidade da Globo, tornando os textos de seus programas tão densos, herméticos e fragmentados que dificultem sua compreensão e consumo em uma mídia como a televisão.

\section{Considerações finais}

É indiscutível a capacitação tecnológica, a qualificada infraestrutura operacional, o alto nível dos profissionais envolvidos, a competência do elenco de atores à disposição para a realização dos produtos ficcionais da Rede Globo.

Mas, e seus produtos? A verdade é que a busca incessante do novo - aliada à adoção de uma grade de programação pré-definida, que se constrói e repete via serialização tanto em seu eixo vertical como no horizontal, semana após semana, mês após mês; a um excesso de fragmentação decorrente da própria serialização e da necessidade de reservar espaço às publicidades, ao marketing social e às chamadas $\mathrm{e}$ 
vinhetas da emissora; à adoção indiscriminada de diferentes tipos de estratégias discursivas; a rapidez com que o desenvolvimento tecnológico vem se traduzindo no contexto dos programas; e à velocidade com que esses produtos são produzidos - vem conferindo ao texto desses produtos ficcionais características bastante peculiares. Há uma superposição e embricamento de diferentes núcleos temáticos na tentativa de abordar de forma pedagógica questões sociais relevantes; há um número excessivo de personagens; há uma neutralização das diferenças econômica, linguística, cultural, étnica, sexual, ou seja, uma eliminação das diversidades, das barreiras racistas ou machistas, em nome da apresentação de um mundo sem castas, sem classes, sem concentração de renda e privilégios; há uma evidente substituição da integridade, da globalidade, da sistematicidade ordenada pela fragmentação; há uma carência de delimitação precisa entre programas e textos promocionais de todo tipo que invadem os programas; há um arrombamento dos limites das narrativas pelas possibilidades de interação com o telespectador/usuário.

A utilização dessas estratégias provoca um estilhaçamento da estrutura narrativa que, então, não só perde seu foco centralizador, como se torna confusa, devido à agregação de um número infindável de personagens com vistas a dar forma a esse embaralhamento e sobreposição de tramas: torna-se difícil até mesmo gravar os nomes, tantos são os participantes das narrativas. Há a supressão dos limites entre o texto do programa e as peças promocionais de diferentes ordens: são diferentes histórias que se superpõem e entrecruzam ao sabor dos interesses e metas da emissora, respondendo a diferentes tipos de expectativas do negócio.

Por outro lado, a intensificação do princípio da obra aberta, possibilitada pelo desenvolvimento tecnológico - que fornece condições, hoje, para se realizar uma aferição mais precisa das expectativas e preferências dos telespectadores, através da interação da televisão com outras plataformas (internet, telefonia celular) e do seu relacionamento com sites, blogs, twitters - interfere fortemente na estruturação dessas narrativas ficcionais, nas escolhas dos procedimentos discursivos a serem adotados. Há um permanente ajustamento da narrativa, a ponto de se desfazerem ou deslocarem pares amorosos que não caíram no gosto do público; de se alterar a posição de personagens, 
que, de principais passam a secundários, ou vice-versa, por falta de empatia com o telespectador; de se eliminarem forçadamente personagens que não caíram na simpatia do público; de se reescreverem ou modificarem os finais desses relatos, moldando-os às preferências do telespectador.

Essas características dificultam, muitas vezes, a percepção desses produtos como um todo de sentido. Associadas à densidade das imagens, à sobrecarga de informações, à intertextualidade feita de referências, alusões, apropriações, ao desdobramento do tempo em uma série de presentes ou em sequências de duração desigual, acabam, muitas vezes, por comprometer a noção mais tradicional de texto como um todo estruturado de sentido, dificultando a percepção global e o entendimento dos conteúdos por parte dos telespectadores, que podem perder o foco central da narrativa. É, assim, nessa perspectiva, que as diferentes lógicas e intenções vêm presidindo a feitura dos produtos ficcionais da emissora acabam por interferir fortemente na estruturação de suas narrativas, nas regras mais elementares da gramática televisual, tão bem conhecidas e partilhadas com o telespectador.

Embora textos desse tipo não esgotem o campo de produção televisual como um todo, convivendo com aqueles outros que preservam uma estrutura mais tradicional, eles, em todo caso, resumem as tendências atuais, apontando rupturas em relação ao modo de dizer televisual, instaurando novas estratégias de discursivização e textualização, ou seja, recorrendo a todo um arsenal de procedimentos para dar conta de interesses, motivações e desejos de inovação na construção das narrativas ficcionais da Globo. Mas, esses procedimentos, empregados de forma tão condensada e maciça, não deixam de colocar em causa a qualidade atual da produção ficcional da Globo, demasiado pretensiosa e rebuscada para os hábitos de consumo do telespectador brasileiro. 


\section{Referências Bibliográficas}

DUARTE, Elizabeth Bastos. Televisão: ensaios metodológicos. Porto Alegre: Sulina, 2004. Col. Estudos sobre o audiovisual.

DUARTE, Elizabeth Bastos; CASTRO, Maria Lília Dias de (orgs). Comunicação audiovisual: gêneros e formatos. Porto Alegre: Sulina, 2007. Col. Estudos sobre o audiovisual.

DUARTE, Elizabeth Bastos; CASTRO, Maria Lília Dias de (orgs). Convergências midiáticas: produção ficcional - RBS TV. Porto Alegre: Sulina, 2010. Col. Estudos sobre o audiovisual.

DUARTE, Elizabeth Bastos; CASTRO, Maria Lília Dias de. Sur la convergence médiatique. Trad. François Jost. Télévision, Paris, CNRS, n. 2, 2011.

FECHINE, Yvana. O Núcleo Guel Arraes e sua "pedagogia dos meios". Revista E-Compós, Associação Nacional dos Programas de Pós-Graduação em Comunicação, n. 8, abr. 2007 (eletrônico).

FONTANILLE, Jacques. Significação e visualidade: exercícios práticos. Porto Alegre: Sulina, 2005. Col. Estudos sobre o audiovisual.

GOES, Tony. Cordel encantado, um encanto de novela.

http://f5.folha.uol.com.br/colunistas/tonygoes/979742-cordel-encantado-um-encanto-de-novela.shtml, UOL, 23.09.2011, acessado em 27.01.2012.

GREIMAS, A. J. A propósito do jogo. Trad. Elizabeth Bastos Duarte. Verso e reverso, São Leopoldo, Unisinos, 1999.

JENKINS, Henry. Cultura da convergência. 2. ed. São Paulo: Aleph, 2009.

JOST, François. La television du quotidien: entre réalité et fiction. Bruxelles: De Boeck Université, 2001.

LACALLE, Charo. As novas narrativas de ficção televisiva e a internet, Revista Matrizes, São Paulo, jan./jul. 2010, p. 79-102.

STYCER, Maurício. Apesar do conflito "ioiô", Cordel encantado termina com merecido reconhecimento. http://televisao.uol.com.br/critica/2011/09/23/apesar-do-conflito-repetitivo-cordel-encantado-terminacom-merecido-reconhecimento.jhtm, UOL, 23.09.2011, acessado em 27.01.2012.

Página da Rede Globo de Televisão. Disponível em: http://redeglobo.globo.com/. Acesso em: 1 ago. 2012.

Wikipédia - Globo. Disponível em: http://pt.wikipedia.org/wiki/Organiza\%C3\%A7\%C3\%B5es_Globo. Acesso em: 1 ago. 2012.

Wikipédia - Padrão Globo de Qualidade. Disponível em: http://pt.wikipedia.org/wiki/Padr

\%C3\%A3o_Globo_de_Qualidade. Acesso em: 1 ago. 2012.

Este artigo e todo o conteúdo da Estudos em Jornalismo e Mídia estão disponíveis em http://www.periodicos.ufsc.br/index.php/jornalismo/index

Estudos em Jornalismo e Mídia está sob a Licença Creative Commons 